\title{
Contribution of human osteoblasts and macrophages to bone matrix degradation and proinflammatory cytokine release after exposure to abrasive endoprosthetic wear particles
}

\author{
ANIKA JONITZ-HEINCKE ${ }^{1}$, KATRIN LOCHNER $^{1}$, CHRISTOPH SCHULZE $^{1,2}$, \\ DIANA POHLE $^{3}$, WERA PUSTLAUK ${ }^{1}$, DORIS HANSMANN ${ }^{1}$ and RAINER BADER ${ }^{1}$ \\ ${ }^{1}$ Department of Orthopedics, Biomechanics and Implant Technology Research Laboratory,
} University Medical Center Rostock, Rostock 18057; ${ }^{2}$ Department of Orthopedic Surgery, Armed Forces Hospital Westerstede, Westerstede 26655; ${ }^{3}$ Department of Immunology, University Medical Center Rostock, Rostock 18057, Germany

Received February 23, 2015; Accepted May 23, 2016

DOI: $10.3892 / \mathrm{mmr} .2016 .5415$

\begin{abstract}
One of the major reasons for failure after total joint arthroplasty is aseptic loosening of the implant. At articulating surfaces, defined as the interface between implant and surrounding bone cement, wear particles can be generated and released into the periprosthetic tissue, resulting in inflammation and osteolysis. The aim of the present study was to evaluate the extent to which osteoblasts and macrophages are responsible for the osteolytic and inflammatory reactions following contact with generated wear particles from Ti-6Al-7Nb and Co-28Cr-6Mo hip stems. To this end, human osteoblasts and THP-1 monocytic cells were incubated with the experimentally generated wear particles as well as reference particles $(0.01$ and $0.1 \mathrm{mg} / \mathrm{ml})$ for $48 \mathrm{~h}$ under standard culture conditions. To evaluate the impact of these particles on the two cell types, the release of different bone matrix degrading matrix metalloproteinases (MMPs), tissue inhibitors of MMPs (TIMPs), and relevant cytokines were determined by multiplex enzyme-linked immunosorbent assays. Following incubation with wear particles, human osteoblasts showed a significant upregulation of MMP1 and MMP8, whereas macrophages reacted with enhanced MMP3, MMP8 and MMP10 production. Moreover, the synthesis of TIMPs 1 and 2 was inhibited. The osteoblasts and macrophages also responded with modified expression of the inflammatory mediators interleukin (IL)-6, IL-8, monocyte chemoattractant protein-1 and vascular endothelial growth factor. These results demonstrate that the release of wear particles affects the release of proinflammatory
\end{abstract}

Correspondence to: Dr Anika Jonitz-Heincke, Department of Orthopedics, Biomechanics and Implant Technology Research Laboratory, University Medical Center Rostock, 142 Doberaner Strasse, Rostock 18057, Germany

E-mail: anika.jonitz@med.uni-rostock.de

Key words: abrasive wear particles, osteolysis, macrophages, osteoblasts, inflammation, matrix degradation, cytokines cytokines and has a negative impact on bone matrix formation during the first $48 \mathrm{~h}$ of particle exposure. Human osteoblasts are directly involved in the proinflammatory cascade of bone matrix degradation. The simultaneous activation and recruitment of monocytes/macrophages boosted osteolytic processes in the periprosthetic tissue. By the downregulation of TIMP production and the concomitant upregulation of MMPs as a response to particle exposure, bone formation around implants may be suppressed, resulting in implant failure.

\section{Introduction}

Currently, total knee and hip replacements are commonly used for the reconstruction of injured or degenerated joints. The tight fixation of the implant to the surrounding tissue is mostly responsible for stable integration into the human body and should preclude micromovements that may lead to the failure of the implant. Implant fixation can be realized via cementless means or with bone cement. The type of implant fixation and the integration into the body by bone ingrowth highly influences the stability and appropriate use of artificial joints. Due to the standard use of artificial joints by the patient, the friction between sliding parts of the implant and the physiological environment, wear particles are produced from various components of the implant or from the bone-implant interface as well as between the bone and cement mantle (1-3). The aseptic loosening of implants due to these particles and tribological products is one of the most common problems occurring in the field of joint endoprosthetics (4). These wear particles can cause osteolytic processes as a result of osteoblastic inhibition and osteoclastic activation (4). Other cell types, including macrophages, fibroblasts, mesenchymal stem cells and lymphocytes are also involved in the osteolytic cascade (5). Wear debris from all orthopedic materials may induce a lot of cellular responses with less specific characteristics of the respective metal and certain types of debris can be more cytotoxic than others $(3,6)$. However, the pathophysiological background has not been fully elucidated and effective therapies are not currently available. Nevertheless, it is well known that various proteins and signaling molecules 
are involved in the osteolytic process. This process includes ostoblast- and macrophage-secreted matrix metalloproteinases (MMPs), of which MMPs 1, 2, 9 and 13 are of particular importance for aseptic implant loosening $(7,8)$. These MMPs are responsible for the degradation of all components of the extracellular matrix resulting in a loss of bone matrix. Additionally, bone resorption, as a response to wear debris, is mediated by cytokines, including tumor necrosis factor (TNF) $\alpha$ and interleukin (IL)-1 $\beta$. Together, they can induce the expression of the receptor activator of nuclear factor- $\kappa \mathrm{B}$ (RANK) ligand (RANKL), which is the general regulator of osteoclast generation as well as activation (9). As a result, these bone-resorbing osteoclasts enhance the matrix degrading effect of MMPs. A number of cytokines and growth factors are involved in the signaling pathway of MMP expression $(10,11)$.

As mentioned above, the RANK/RANKL/osteoprotegerin (OPG) system is important in the differentiation of osteoclasts (12). Osteoblasts synthesize the effector protein RANKL, which can bind to the RANK receptor on osteoclastic progenitor cells. OPG, also expressed by osteoblasts, is able to bind RANKL inhibiting its binding to RANK (13). Therefore, the RANK/RANKL/OPG system is another effector system to sustain the periprosthetic balance between bone resorption and formation (14).

Wear debris also affects osteoblasts, which are negatively influenced by decreasing the synthetic capacity of collagen type 1 , the major component of bone extracellular matrix (4,15-17). Additionally, the apoptosis rate of osteoblasts is clearly increased $(4,17)$.

As extracellular matrix degradation and remodeling processes around implants have been considered the main biological events during periprosthetic loosening (5), the aim of the present study was to analyze the influence of different wear particles on the expression of matrix degrading MMPs and proinflammatory cytokines in human osteoblasts and macrophages. Monocytes/macrophages are the predominant cells involved in inflammatory particle-induced osteolysis due to their phagocytic role and cytokine release $(6,18,19)$. In the current study, it was determined which of these two cell types was more responsible for increased cytokine and MMP expression, and thus for the stimulation of matrix degradation. Furthermore, it was determined which type of MMP was induced by wear particles in the two cell types.

In contrast to other studies conducted using commercially available particles, particles generated from various implant materials (titanium and cobalt chromium alloys) were used. Following exposure of human osteoblasts and monocytes/macrophages to these particles, the release of different MMPs and cytokines was analyzed. Additionally, the release of tissue inhibitors of MMPs (TIMPs) and their impact on MMP inhibition was determined.

\section{Materials and methods}

Generation and preparation of abrasive wear particles. Particles were generated by simulating the interfacial wear between total hip stems and bone cement using a special wear simulator (1). For particle generation, standard total hip stems made of either a titanium alloy (Ti-6Al-7Nb) or a Cobalt-Chromium alloy (Co-28Cr-6Mo) were used (20).
The implants were straight stems characterized by a defined surface roughness $(\mathrm{Rz})$ value of $\sim 7 \mu \mathrm{m}$ (smooth surface, Co-28Cr-6Mo) and $20 \mu \mathrm{m}$ (rough surface, Ti-6Al-7Nb) were used. The total hip stems were cemented with commercially available polymethylmethacrylate (PMMA) bone cement (Palacos ${ }^{\circledR}$ R, Hereaus Kulzer GmbH, Wehrheim, Germany), containing $15 \%$ zirconiumoxide $\left(\mathrm{ZrO}_{2}\right)$ particles as a radio-opaque additive.

Prior to cell biological experiments, the quantities of metallic particles from the generated wear debris (a conglomerate of metallic and bone cement particles) were determined by atomic absorption spectroscopy and were shown to be $424 \pm 93 \mu \mathrm{g}$ Ti for Ti-6Al-7Nb stems and $376 \pm 83 \mu \mathrm{g}$ Co for Co-28Cr-6Mo stems (21). Additionally, $>99 \%$ of the total particles were non-metallic (21). The mean particle size was determined by size distribution measurements and ranged from $2.8 \mu \mathrm{m}$ (Co-28Cr-6Mo) to $4.4 \mu \mathrm{m}$ (Ti-6Al-7Nb) whereby $90 \%$ of the particles were $<15 \mu \mathrm{m}(21)$.

Moreover, commercially pure titanium powder with an average particle size of $3 \mu \mathrm{m}$ (cp-Ti; Grade E, dry; Chemetall $\mathrm{GmbH}$, Frankfurt, Germany), pure polycrystalline $\mathrm{ZrO}_{2}$ particles with mean size of $1.75 \mu \mathrm{m}$ (Selectipur, Hereaus Kulzer $\mathrm{GmbH}$ ), as well as particles from PMMA (Hereaus Kulzer $\mathrm{GmbH})$ and titanium dioxide $\left(\mathrm{TiO}_{2}\right)$ with a mean size of $1.8 \mu \mathrm{m}$ (BioCer Entwicklungs-GmbH, Bayreuth, Germany) were used as references.

Generated wear particles and commercially available reference particles (5 $\mathrm{mg}$ of each) were sterilized using gamma radiation. Subsequently, a stock solution $(10 \mathrm{mg} / \mathrm{ml})$ was prepared by suspending the particles in $0.5 \mathrm{ml}$ sterile phosphate-buffered saline (PAA Laboratories $\mathrm{GmbH}$, Coelbe, Germany). Further dilutions with cell culture medium created the final particle concentrations of 0.1 and $0.01 \mathrm{mg} / \mathrm{ml}$.

Isolation and cultivation of human primary osteoblasts. Human primary osteoblasts were isolated under sterile conditions from bone marrow-derived femoral heads of patients undergoing primary total hip replacement. All samples were collected after participants had signed written informed consent forms and approval by the Local Ethical Committee of the University of Rostock (Rostock, Germany; no. AZ: 2010-10) had been obtained.

Cancellous bone was extracted from femoral heads, suspended in sterile phosphate-buffered saline (PBS) and washed twice. Osteoblasts were obtained using the protocol of Lochner et al (4).

Freshly isolated osteoblast-like cells were plated in $25 \mathrm{~cm}^{2}$ culture flasks in $8 \mathrm{ml}$ osteogenic medium (Dulbecco's modified Eagle's medium; Biochrom AG Biotechnologie, Berlin, Germany), supplemented with $10 \%$ fetal calf serum, $1 \%$ penicillin/streptomycin, $1 \%$ amphotericin B, $1 \%$ HEPES, $50 \mu \mathrm{g} / \mathrm{ml}$ ascorbic acide, $10 \mathrm{~mm} \beta$-glycerophosphate and $100 \mathrm{nM}$ dexamethasone, and were incubated at $37^{\circ} \mathrm{C}$ in a humidified atmosphere of $5 \% \mathrm{CO}_{2}$ and $95 \%$ air. The culture medium was changed every other day and non-adherent cells were aspirated. The progress of proliferation was determined by microscopy. When a confluency of $90 \%$ was reached, the cells were subcultured at a ratio of 1:6. The cultivated cells were used in experiments at passage three. To verify the osteogenic character of isolated cells, alkaline 
phosphatase staining with fuchsin and substrate chromogen (Dako, Hamburg, Germany) was performed, according to the manufacturer's instructions. To exclude the presence of monocytes/macrophages in the osteoblastic culture, flow cytometry was performed on representative samples from two donors (4). Since in the primary cell cultures, no CD68 positive cells (selective for monocytes) and only $2.4 \%$ CD14 positive cells (selective for monocytes and macrophages) were detected, a contamination of human primary osteoblasts with monocytes/macrophages could be excluded (4).

For in vitro experiments, osteoblasts were transferred to 96-well plates with 3,000 cells per well in $200 \mu \mathrm{l}$ complete medium. The human osteoblasts were allowed to adhere for $24 \mathrm{~h}$ at which time the particle-free medium was replaced with particle-containing medium for $48 \mathrm{~h}$. Osteoblasts incubated with normal culture medium served as test controls.

Supernatants from osteoblasts incubated with particle-containing medium were investigated for the expression of cytokines IL-6, IL-8, monocyte chemoattractant protein-1 (MCP1) and vascular endothelial growth factor (VEGF), as well as for the synthesis of MMPs 1, 3, 8 and 10, and their inhibitors, TIMPs 1-4. These data were collected to assess whether osteoblasts, being bone-forming cells, contribute with their induction of osteoclast differentiation and matrix resorption to osteolysis following contact with abrasive wear particles.

Cultivation of human monocytes/macrophages. The THP-1 monocytic cell line is an ideal cell line for differentiation experiments of macrophages as it is similar in morphology and metabolism to macrophages. Therefore, differentiated THP-1 macrophages have already been used in several in vitro studies concerning macrophage involvement in inflammatory processes (22). To induce differentiation within $48 \mathrm{~h}$ of incubation, phorbol 12-myristate 13-acetate (PMA) can be used (22).

In the present experiments, THP-1 cells (American Type Culture Collection, Rockville, MD, USA) were maintained in continuous culture in RPMI-1640 medium (Biochrom AG Biotechnologie) supplemented with $10 \%$ fetal calf serum (FCS), $100 \mathrm{U} / \mathrm{ml} \mathrm{L-glutamine,} 200 \mathrm{mU} / \mathrm{ml}$ penicillin and $0.2 \mathrm{mg} / \mathrm{ml}$ streptomycin. Cells were incubated at $37^{\circ} \mathrm{C}$ in a humidified atmosphere of $5 \% \mathrm{CO}_{2}$ and $95 \%$ air. For differentiation into macrophage-like adherent cells, THP-1 cells were transferred into 6 -well plates with $2 \times 10^{6}$ cells per well in $3 \mathrm{ml}$ differentiation medium. Differentiation medium was composed of RPMI-1640 and supplements, as well as $25 \mathrm{nM}$ PMA for the maturation of monocytes into macrophage-like adherent cells. All medium contents were purchased from PAA Laboratories GmbH (Linz, Austria).

Following differentiation into macrophage-like cells within $48 \mathrm{~h}$, the particle-free differentiation medium was replaced with the respective particle-containing medium (stem-derived wear particles and commercially available reference particles) for a further $48 \mathrm{~h}$. Macrophages incubated with normal culture medium served as test controls.

Supernatants from the macrophage culture were investigated for the expression of cytokines (IL-6, IL-8, MCP1 and VEGF) as well as for the synthesis of MMPs 1, 3, 8, 10 and 13, and their inhibitors, TIMPs 1-4. These data were collected to assess the extent to which macrophages contribute to matrix resorption and osteolysis after contact with abrasive wear particles.

Protein detection using multiplex technology. The effects of particle exposition on the release of cytokines (IL-6, IL-8, MCP1 and VEGF), ECM-degrading MMPs (MMPs 1, 3, 8, 9 and 10) and endogenous TIMPs (TIMP 1, 2, 3 and 4) were analyzed by Multiplex enzyme-linked immunosorbent assays. Therefore, the supernatants of osteoblasts and macrophage-like cells were quantified after $48 \mathrm{~h}$ of incubation using the Multiplex Cytokine Assay (Bio-Plex Pro Human Cytokines Group I 5-plex, Bio-Rad Laboratories Inc., Munich, Germany), the Multiplex MMP Assay (WideScreen Human MMP Panel, Novagen, Merck Chemicals Ltd., Nottingham, UK) and the Fluorokine MAP Human TIMP Multiplex kit (R\&D Systems, Abingdon, UK). All assays are based on simultaneous detection of different mediators in a single well of a 96-well microplate involving fluorochrome-labeled microsphere beads. For the assays, osteoblast or macrophage supernatants, standard solutions, and blanks were dispensed into the corresponding wells of a 96-well filter plate already containing anti-cytokine/MMP/TIMP-conjugated beads. The assays were performed according to the manufacturer's instructions. The concentration of cytokines, MMPs and TIMPs were finally detected by the Bio-Plex 200 system using the Bio-Plex Manager software 4.1.1 (both from Bio-Rad Laboratories Inc., Munich, Germany). Protein concentrations were calculated using a standard curve derived from a recombinant standard supported by the multiplex assays.

Data illustration and statistical analysis. Data are presented as box plots. Boxes denote interquartile ranges, horizontal lines within the boxes denote medians, and whiskers denote minimum and maximum values. For all analyses, cultures of human osteoblasts from a minimum of three independent donors and of the THP-1 cell line from a minimum of three independent experiments were used (in duplicates). Since the data obtained were not normally distributed, the statistical significance between two datasets was calculated with the Mann-Whitney U test using SPSS 20 (IBM Deutschland, Ehningen, Germany). $\mathrm{P} \leq 0.05$ was considered to indicate a statistically significant difference.

\section{Results}

MMP expression by human osteoblasts and macrophages. MMPs are zinc-dependent proteases that degrade, among other proteins, collagens of the extracellular matrix. After $48 \mathrm{~h}$ of particle exposure, the levels of MMPs were determined by a multiplex ELISA.

Compared with unstimulated cells, MMP1 expression was significantly induced following exposure to a higher concentration $(0.1 \mathrm{mg} / \mathrm{ml})$ of the cpTi reference particles (osteoblasts: 1.2-fold increase, $\mathrm{P}=0.014$; macrophages: 1.6-fold increase, $\mathrm{P}=0.005$ ) and $\mathrm{TiO}_{2}$ (macrophages: 1.2-fold increase, $\mathrm{P}=0.005$ ) as well as from hip stem-derived particles of Ti-6Al-7Nb (osteoblasts: 3.4 -fold increase, $\mathrm{P}=0.014$ macrophages: 1.9 -fold increase, $\mathrm{P}=0.005$ ) in the two cell types. Furthermore, significant differences between particle concentrations were observed following exposure to particles from cpTi $(\mathrm{P}=0.021)$ 

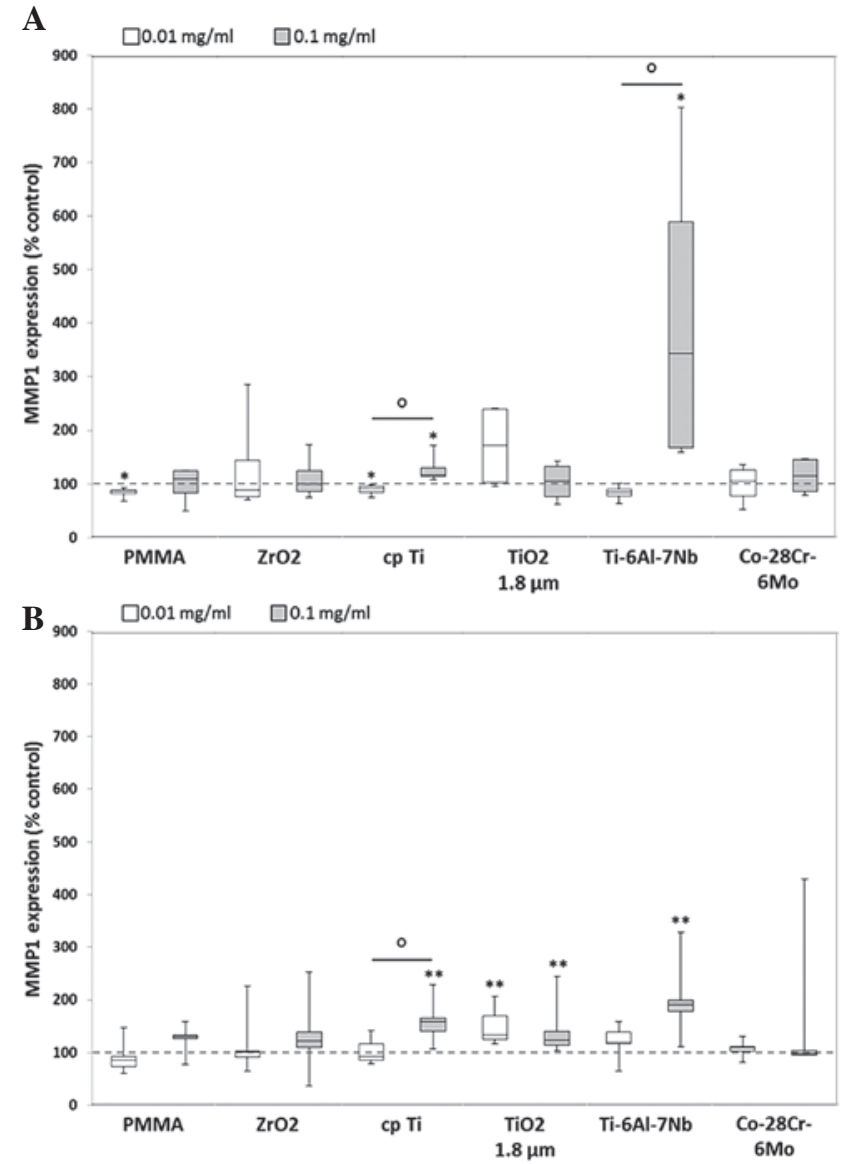

Figure 1. Release of MMP1 by human (A) osteoblasts and (B) macrophages. Cells were cultivated under standard culture conditions and later treated with the respective particles for $48 \mathrm{~h}$. Subsequently, cell culture supernatants were collected and analyzed using multiplex enzyme-linked immunosorbent assays (osteoblasts, $n=4$; macrophages, $n=3$ ). MMP1 contents are displayed relative to the untreated control. Data are presented as box plots. ${ }^{*} \mathrm{P} \leq 0.05$ and ${ }^{* *} \mathrm{P}<0.01$ vs. particle exposure. ${ }^{\circ} \mathrm{P} \leq 0.05$ vs. $0.01 \mathrm{mg} / \mathrm{ml}$ (Mann-Whitney $\mathrm{U}$ test). MMP, matrix metalloproteinase; PMMA, polymethylmethacrylate; $\mathrm{ZrO}_{2}$, zirconiumoxide; $\mathrm{TiO}_{2}$, titanium dioxide.

and Ti-6Al-7Nb $(\mathrm{P}=0.021)$ in osteoblasts as well as for $\mathrm{cpTi}$ particles $(\mathrm{P}=0.028)$ in macrophages. By contrast, particles from Co-28Cr-6Mo stems as well as reference particles from PMMA and $\mathrm{ZrO}_{2}$ did not induce MMP1 expression in human osteoblasts and macrophages (Fig. 1). MMP3 protein was mostly downregulated in human osteoblasts following exposure to reference and hip stem-derived particles. Significant differences compared with unstimulated cells were shown for the lower particle concentration of cpTi ( 0.8 -fold decrease, $\mathrm{P}=0.014), \mathrm{TiO}_{2}$ (0.8-fold decrease, $\mathrm{P}=0.014$ ), Ti-6Al-7Nb (0.7-fold decrease, $\mathrm{P}=0.014)$ and $\mathrm{Co}-28 \mathrm{Cr}-6 \mathrm{Mo}$ (0.5-fold decrease, $\mathrm{P}=0.014)$. Additionally, concentration-dependent differences were visible for $\mathrm{ZrO}_{2}$ [1.2-fold increase $(0.01 \mathrm{mg} / \mathrm{ml})$ vs. 0.8 -fold decrease $(0.1 \mathrm{mg} / \mathrm{ml}), \mathrm{P}=0.043]$ and $\mathrm{TiO}_{2}[0.8$-fold decrease $(0.01 \mathrm{mg} / \mathrm{ml})$ vs. 0.2 -fold increase $(0.1 \mathrm{mg} / \mathrm{ml}), \mathrm{P}=0.043]$ particles (Fig. 2A). In human macrophages, particle exposure resulted in an increase in MMP3 protein (Fig. 2B); a greater higher particle concentration generally resulted in increased MMP3 levels, particularly with titanium-based particles [cpTi: 1.1 -fold increase $(0.01 \mathrm{mg} / \mathrm{ml}), 2$-fold increase, $\mathrm{P}=0.005(0.1 \mathrm{mg} / \mathrm{ml})$; and $\mathrm{TiO}_{2}: 1.6$-fold increase $(0.01 \mathrm{mg} / \mathrm{ml}), 1.9$-fold increase $(0.1 \mathrm{mg} / \mathrm{ml})$; both $\mathrm{P}=0.005]$.
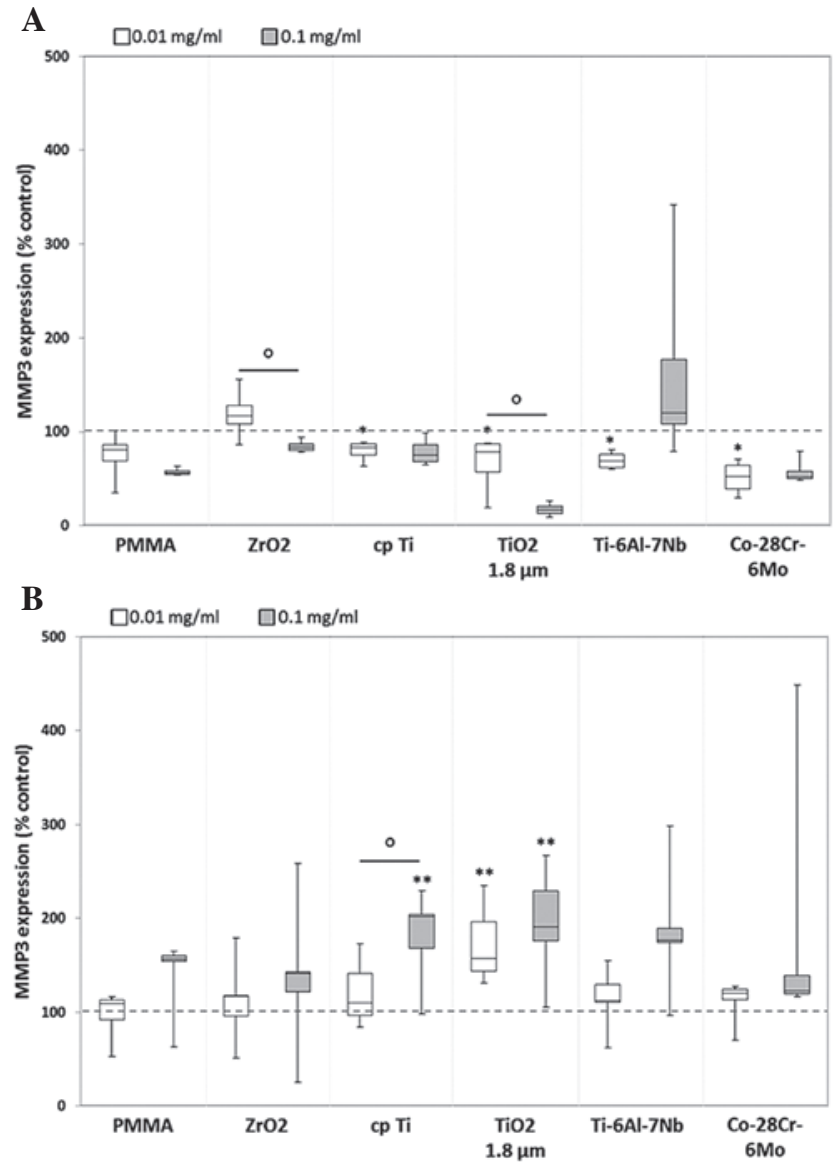

Figure 2. Release of MMP3 by human (A) osteoblasts and (B) macrophages. Cells were cultivated under standard culture conditions and later treated with the respective particles for $48 \mathrm{~h}$. Subsequently, cell culture supernatants were collected and analyzed using multiplex enzyme-linked immunosorbent assays (osteoblasts, $n=4$; macrophages, $n=3$ ). MMP3 contents are displayed relative to the untreated control. Data are presented as box plots. ${ }^{*} \mathrm{P} \leq 0.05$ and ${ }^{* *} \mathrm{P}<0.01$ vs. particle exposure. ${ }^{\circ} \mathrm{P} \leq 0.05$ vs. $0.01 \mathrm{mg} / \mathrm{ml}$ (Mann-Whitney $\mathrm{U}$ test). MMP, matrix metalloproteinase; PMMA, polymethylmethacrylate; $\mathrm{ZrO}_{2}$, zirconiumoxide; $\mathrm{TiO}_{2}$, titanium dioxide.

Compared with unstimulated cells, MMP8 protein expression was induced in human osteoblasts following exposure to all particles, with the exception of cpTi $(0.01 \mathrm{mg} / \mathrm{ml}: 0.9$-fold decrease) and $\mathrm{TiO}_{2}(0.1 \mathrm{mg} / \mathrm{ml}$ : 0.9-fold decrease). A significant upregulation was determined for particles from $\mathrm{ZrO}_{2}$ $(0.1 \mathrm{mg} / \mathrm{ml}: 1.2$-fold, $\mathrm{P}=0.029)$ and Ti-6Al-7Nb $(0.1 \mathrm{mg} / \mathrm{ml}$ : 1.5 -fold, $\mathrm{P}=0.029)$ following exposure to the higher particle concentration. In human macrophages, a concentration-dependent upregulation of MMP8 protein was also determined following treatment with reference and Ti-6Al-7Nb particles, with higher protein levels following exposure to the higher particle concentration [PMMA: 0.8 -fold decrease, $\mathrm{P}=0.008$ $(0.01 \mathrm{mg} / \mathrm{ml})$ vs. 1.2 -fold increase $(0.1 \mathrm{mg} / \mathrm{ml}) ; \mathrm{ZrO}_{2}$ : 1.0 -fold $(0.01 \mathrm{mg} / \mathrm{ml})$ vs. 1.3 -fold increase $(0.1 \mathrm{mg} / \mathrm{ml}) ; \mathrm{cpTi}$ : 0.9 -fold decrease $(0.01 \mathrm{mg} / \mathrm{ml})$ vs. 1.3 -fold increase, $\mathrm{P}=0.008$ $(0.1 \mathrm{mg} / \mathrm{ml}), \mathrm{P}=0.032(0.01 \mathrm{mg} / \mathrm{ml}$ vs. $0.1 \mathrm{mg} / \mathrm{ml}) ; \mathrm{Ti}-6 \mathrm{Al}-7 \mathrm{Nb}$ : 1.1-fold increase $(0.01 \mathrm{mg} / \mathrm{ml})$ vs. 1.4 -fold increase $(0.1 \mathrm{mg} / \mathrm{ml})$ ] (data not shown).

Furthermore, synthesis of MMP10 protein was downregulated in human osteoblasts for all particles except for $\mathrm{ZrO}_{2}$ $(0.01 \mathrm{mg} / \mathrm{ml}: 1.5$-fold increase) and Ti-6Al-7Nb $(0.1 \mathrm{mg} / \mathrm{ml}$ : 11-fold increase) particles, which resulted in increased MMP10 

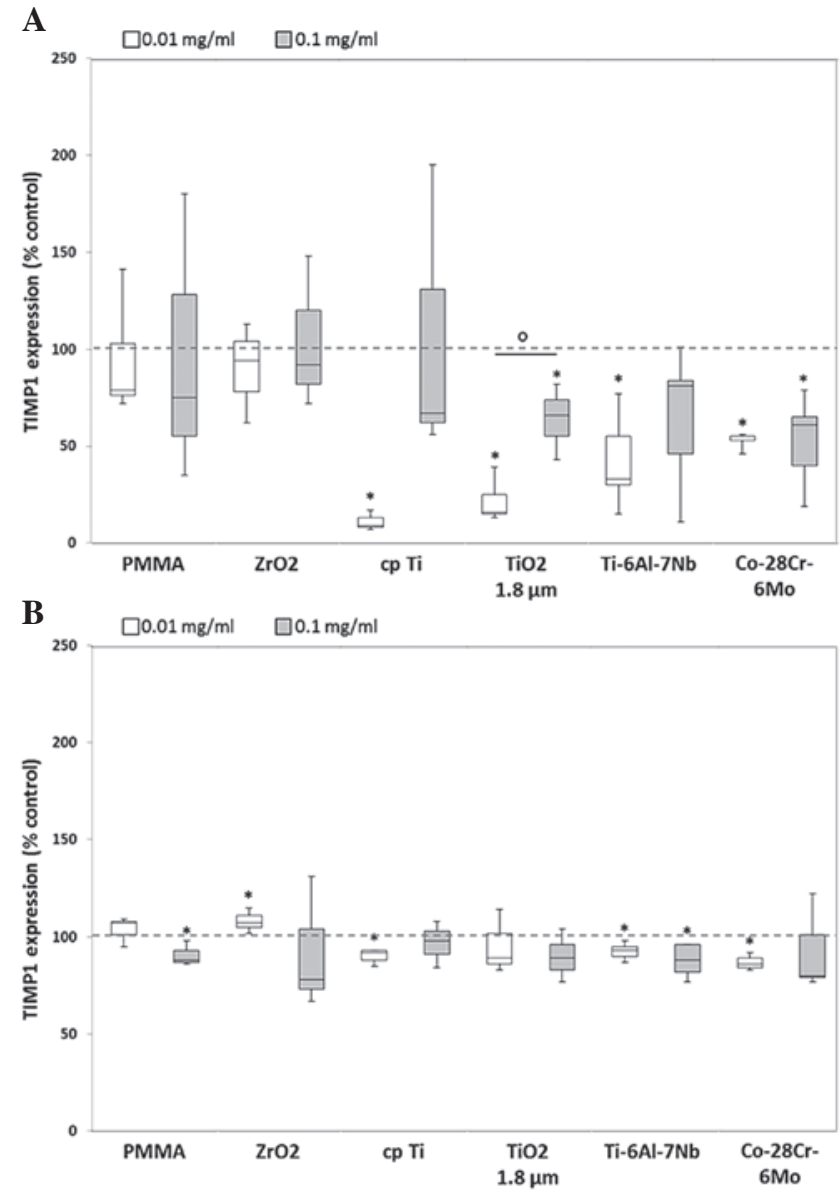

Figure 3. Release of TIMP1 by human (A) osteoblasts and (B) macrophages Cells were cultivated under standard culture conditions and later treated with the respective particles for $48 \mathrm{~h}$. Subsequently, cell culture supernatants were collected and analyzed using multiplex enzyme-linked immunosorbent assays (osteoblasts, $n=4$; macrophages, $n=3$ ). TIMP1 contents are displayed relative to the untreated control. Data are presented as box plots. " $\mathrm{P} \leq 0.05$ vs. unstimulated control. ${ }^{\circ} \mathrm{P} \leq 0.05$ vs. $0.01 \mathrm{mg} / \mathrm{ml}$ (Mann-Whitney U test) TIMP1, tissue inhibitor of matrix metalloproteinase 1; PMMA, polymethylmethacrylate; $\mathrm{ZrO}_{2}$, zirconiumoxide; $\mathrm{TiO}_{2}$, titanium dioxide.

expression following exposure. In human macrophages, MMP10 protein content was increased following exposure to all particles with a tendency for higher protein amounts following stimulation with $0.1 \mathrm{mg} / \mathrm{ml}$ particle suspension compared with $0.01 \mathrm{mg} / \mathrm{ml}$ [PMMA: 1.0-fold vs. 1.3-fold, $\mathrm{ZrO}_{2}$ : 1.0-fold vs. 1.3-fold, cpTi: 1.0 -fold vs. 1.5 -fold, Ti-6Al-7Nb: 1.2 -fold vs. 1.6-fold, Co-28Cr-6Mo: 1.1-fold vs. 1.2 -fold, all $0.01 \mathrm{mg} / \mathrm{ml}$ vs. $0.1 \mathrm{mg} / \mathrm{ml}$, respectively] (data not shown).

Finally, induction of MMP13 protein expression was only observed in human macrophages following exposure to $\mathrm{TiO}_{2}$ (0.01 mg/ml: 1.2 -fold; $0.1 \mathrm{mg} / \mathrm{ml}: 1.5$-fold) and Ti-6Al-7Nb (0.01 mg/ml: 1.2-fold) particles; however, this was not identified to be significantly different compared with the unstimulated control (data not shown).

Expression of TIMPs. The effects of MMPs are naturally inhibited by endogenous TIMPs, which comprise a family of four specific members. Thus, the activity of MMPs is regulated by the binding of TIMPs (23).

Expression of TIMP1 and TIMP2 was decreased in the two cell types compared with unstimulated cells. After
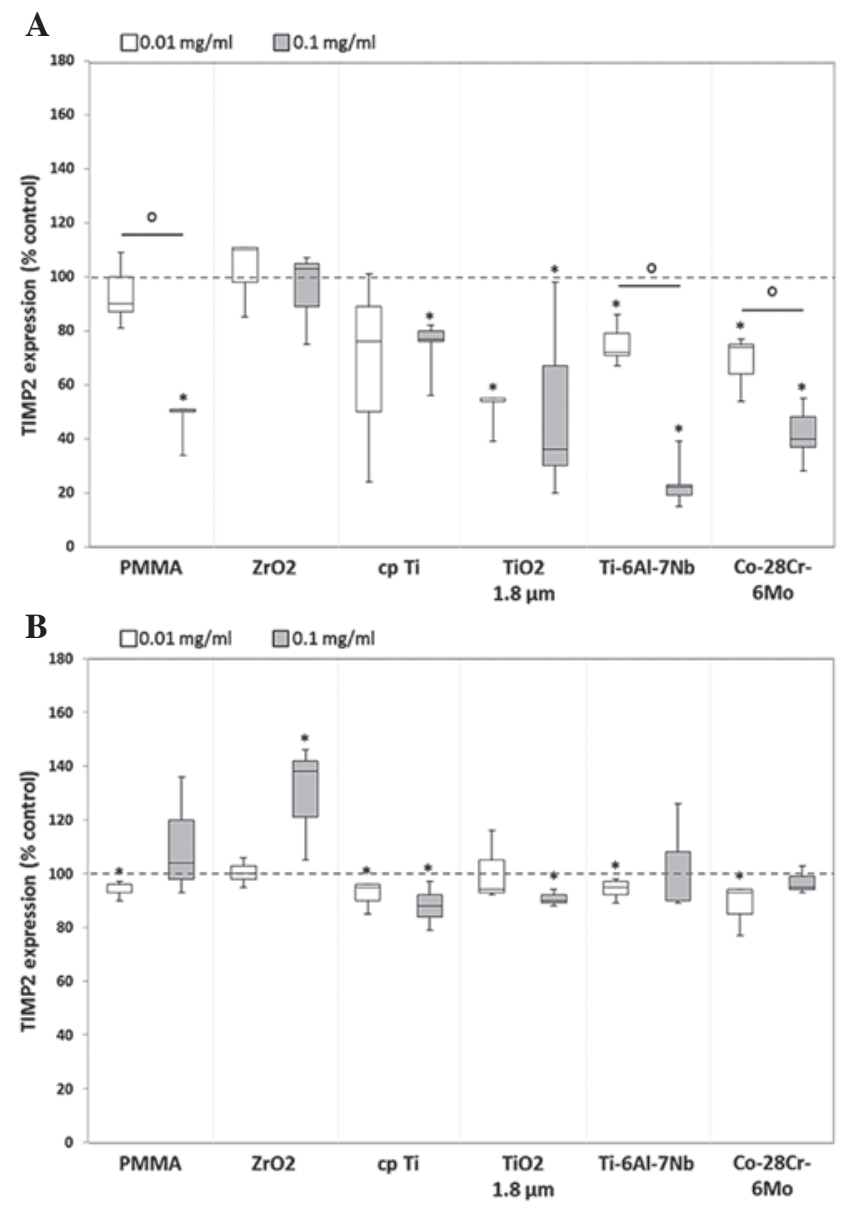

Figure 4. Release of tissue inhibitor of TIMP2 by human (A) osteoblasts and (B) macrophages. Celles were cultivated under standard culture conditions and later treated with the respective particles for $48 \mathrm{~h}$. Subsequently, cell culture supernatants were collected and analyzed using multiplex enzyme-linked immunosorbent assays (osteoblasts, $n=4$; macrophages, $n=3$ ). TIMP 2 contents are displayed relative to the untreated control. Data are presented as box plots. ${ }^{*} \mathrm{P} \leq 0.05$ vs. particle exposure. ${ }^{\circ} \mathrm{P} \leq 0.05$ vs. $0.01 \mathrm{mg} / \mathrm{ml}$ (Mann-Whitney U test). TIMP2, tissue inhibitor of matrix metalloproteinase 2; PMMA, polymethylmethacrylate; $\mathrm{ZrO}_{2}$, zirconiumoxide; $\mathrm{TiO}_{2}$, titanium dioxide.

exposure to the lower particle concentration, a significant decrease in TIMP1 content in human osteoblasts was shown for cpTi (0.09-fold), $\mathrm{TiO}_{2}$ (0.16-fold), Ti-6Al-7Nb (0.33-fold) and $\mathrm{Co}-28 \mathrm{Cr}-6 \mathrm{Mo}$ (0.55-fold) (all $\mathrm{P}=0.014$; Fig. $3 \mathrm{~A})$. In human macrophages, a significant reduction of TIMP1 could be shown for all particles except for $\mathrm{ZrO}_{2}$. Here, marginally increased levels of $\mathrm{ZrO}_{2}(0.01 \mathrm{mg} / \mathrm{ml}: 1.1$-fold $)$ were determined following exposure to lower particle concentrations (Fig. 3B).

The TIMP2 expression level in human osteoblasts showed a greater decrease when exposed to the higher dose of each particle (Fig. 4A). Significant differences between the two particle concentrations could be shown following exposure to particles from PMMA [0.9-fold decrease $(0.01 \mathrm{mg} / \mathrm{ml})$ vs. 0.5 -fold decrease $(0.1 \mathrm{mg} / \mathrm{ml}) ; \mathrm{P}=0.029)$, Ti-6Al-7Nb [0.7-fold decrease $(0.01 \mathrm{mg} / \mathrm{ml})$ vs. 0.2 -fold decrease $(0.1 \mathrm{mg} / \mathrm{ml})$; $\mathrm{P}=0.021)$ and Co-28Cr-6Mo $(0.7$-fold decrease $(0.01 \mathrm{mg} / \mathrm{ml})$ vs. 0.4 -fold decrease $(0.1 \mathrm{mg} / \mathrm{ml}) ; \mathrm{P}=0.043]$. In human macrophages, a similar expression profile to that of TIMP1 was visible for TIMP2. Except for $\mathrm{ZrO}_{2}(0.1 \mathrm{mg} / \mathrm{ml}$ : 1.4 -fold increase, $\mathrm{P}=0.037$ ), slightly decreased or constant protein 

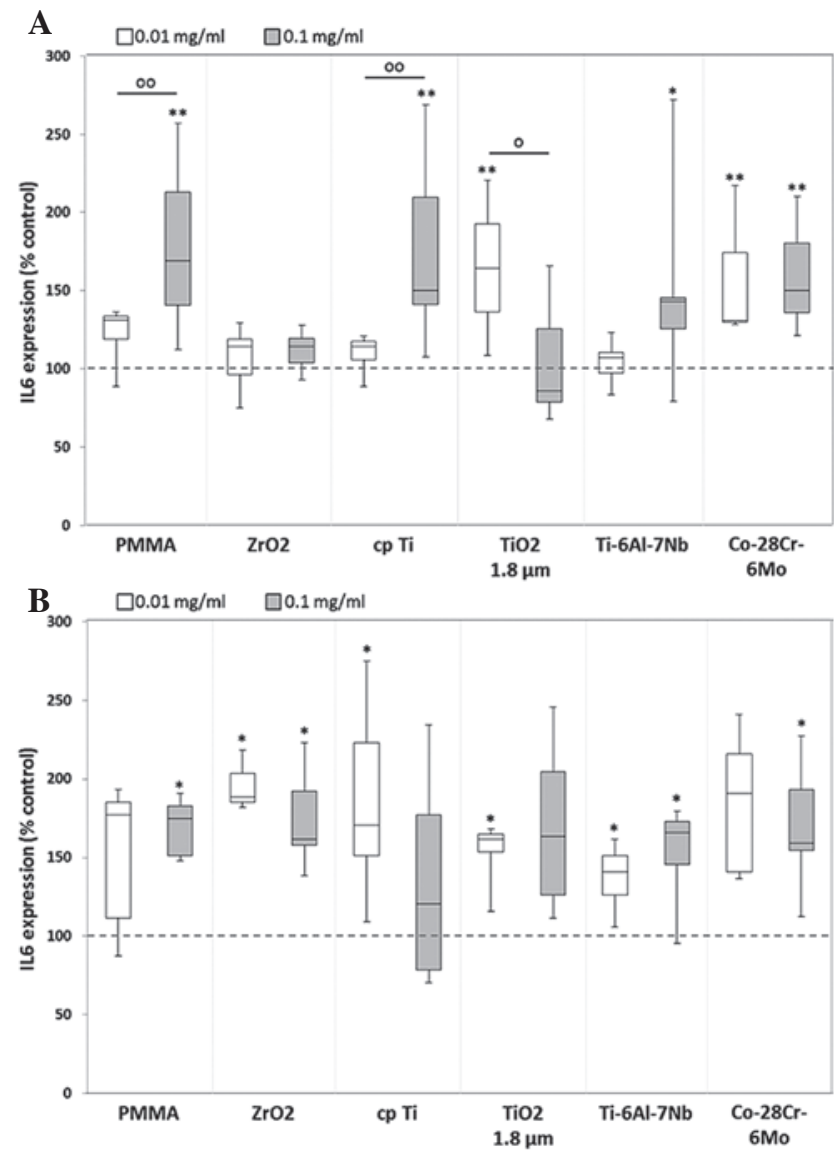

Figure 5. Release of IL-6 by human (A) osteoblasts and (B) macrophages. Cells were cultivated under standard culture conditions and later treated with the respective particles for $48 \mathrm{~h}$. Subsequently, cell supernatants were collected and analyzed using multiplex enzyme-linked immunosorbent assays (osteoblasts, $\mathrm{n} \geq 3$; macrophages, $\mathrm{n}=3$ ). IL- 6 contents are displayed relative to the untreated control. Data are presented as box plots. ${ }^{*} \mathrm{P} \leq 0.05$ and ${ }^{* *} \mathrm{P}<0.01$ vs. particle exposure. ${ }^{\circ} \mathrm{P} \leq 0.05$ and ${ }^{\circ} \mathrm{P}<0.01$ vs. $0.01 \mathrm{mg} / \mathrm{ml}$ (Mann-Whitney $\mathrm{U}$ test). IL-6, interleukkin-6; PMMA, polymethylmethacrylate; $\mathrm{ZrO}$, zirconiumoxide; $\mathrm{TiO} 2$, titanium dioxide.

amounts (compared with the unstimulated control) were determined following particle exposure without dose-dependent differences (Fig. 4B). For TIMP3 and TIMP4, no protein expression was identified in human osteoblasts and macrophages following particle exposure.

Release of cytokines following particle exposure. Particle-induced communication among cells, such as osteoblasts and macrophages, resulted in the production of proinflammatory cytokines, including IL-6, IL-8 and MCP1 (24). Regarding the IL-6 release from human osteoblasts, a significant upregulation in the protein level was determined following particle exposure, except in the case of $\mathrm{ZrO}_{2}$. Compared with unstimulated cells, higher concentrations $(0.1 \mathrm{mg} / \mathrm{ml})$ of hip stem-derived particles resulted in a higher IL-6 synthesis rate (Ti-6Al-7Nb: 1.4-fold, $\mathrm{P}=0.017$; Co-28Cr-6Mo: 1.5-fold) in human osteoblasts (Fig. 5A). Additionally, significant dose-dependent differences were observed following exposure to the reference particles PMMA [1.3-fold increase $(0.01 \mathrm{mg} / \mathrm{ml})$ vs. 1.7-fold increase $(0.1 \mathrm{mg} / \mathrm{ml}), \mathrm{P}=0.009]$, cpTi [1.1-fold increase $(0.01 \mathrm{mg} / \mathrm{ml})$ vs. 1.5 -fold increase $(0.1 \mathrm{mg} / \mathrm{ml}), \mathrm{P}=0.009]$ and $\mathrm{TiO}_{2}$ [1.6-fold
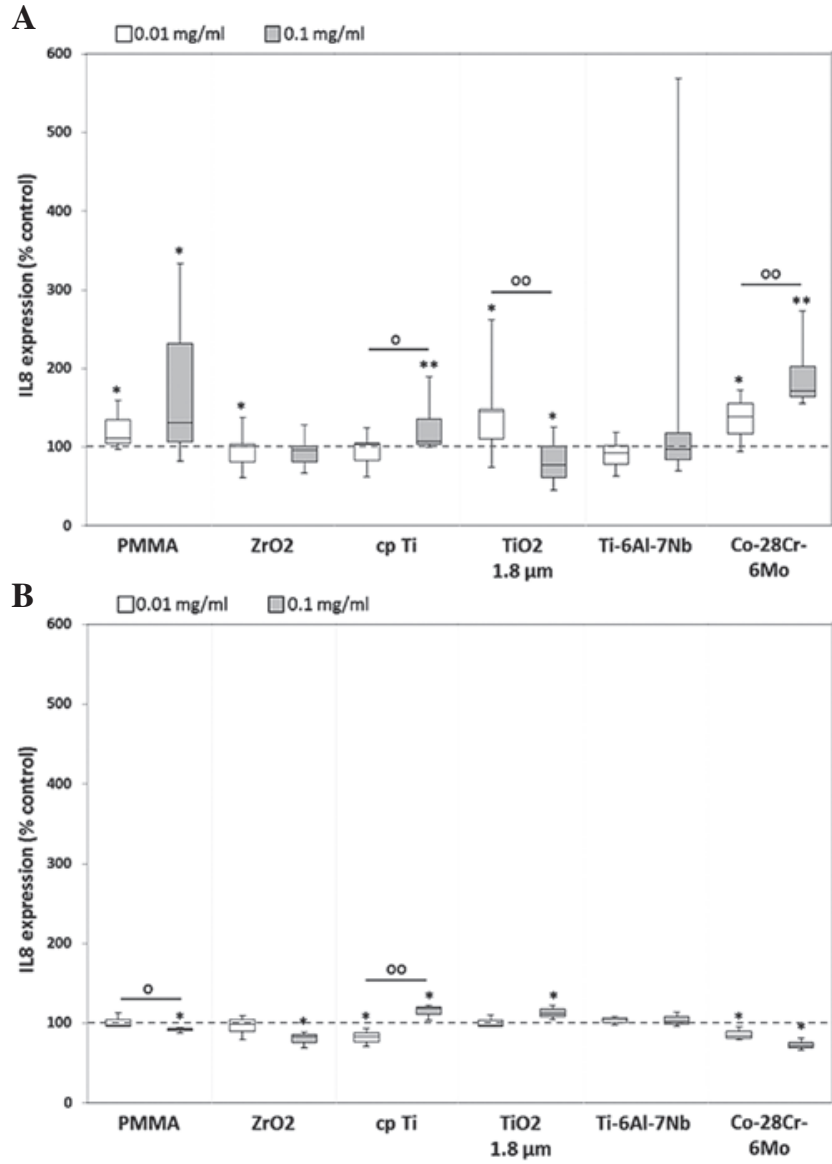

Figure 6. Release of IL-8 by human (A) osteoblasts and (B) macrophages. Cells were cultivated under standard culture conditions and later treated with the respective particles for $48 \mathrm{~h}$. Subsequently, cell culture supernatants were collected and analyzed using multiplex enzyme-linked immunosorbent assays (osteoblasts, $\mathrm{n} \geq 3$; macrophages, $\mathrm{n}=3$ ). IL-8 contents are displayed relative to the untreated control. ${ }^{*} \mathrm{P} \leq 0.05$ and ${ }^{* *} \mathrm{P}<0.01$ vs. particle exposure. ${ }^{\circ} \mathrm{P} \leq 0.05$ and ${ }^{\circ} \mathrm{P}<0.01$ vs. $0.01 \mathrm{mg} / \mathrm{ml}$ (Mann-Whitney U test). IL-8, interleukin 8; PMMA, polymethylmethacrylate; $\mathrm{ZrO}_{2}$, zirconiumoxide; $\mathrm{TiO}_{2}$, titanium dioxide.

increase $(0.01 \mathrm{mg} / \mathrm{ml})$ vs. 0.9 -fold decrease $(0.1 \mathrm{mg} / \mathrm{ml})$, $\mathrm{P}=0.013]$. In human macrophages, a significant increase in IL-6 protein content was visible after treatment with all reference particles as well as hip stem-derived particles compared with unstimulated cells (Fig. 5B).

Following particle exposure, significant differences in IL-8 protein levels between particle concentrations were shown for cpTi [1.0-fold $(0.01 \mathrm{mg} / \mathrm{ml})$ vs. 1.1-fold increase $(0.1 \mathrm{mg} / \mathrm{ml})$, $\mathrm{P}=0.013], \mathrm{TiO}_{2}$ [1.5-fold increase $(0.01 \mathrm{mg} / \mathrm{ml})$ vs. 0.8 -fold decrease $(0.1 \mathrm{mg} / \mathrm{ml}), \mathrm{P}=0.009$ ] and $\mathrm{Co}-28 \mathrm{Cr}-6 \mathrm{Mo}$ [1.4-fold increase $(0.01 \mathrm{mg} / \mathrm{ml})$ vs. 1.7 -fold increase $(0.1 \mathrm{mg} / \mathrm{ml}), \mathrm{P}=0.006$ ] (Fig. 6A). In human macrophages, a tendency towards IL-8 downregulation was visible, with the exception of significant increases in the titanium references (cpTi: 1.2 -fold, $\mathrm{P}=0.037$; and $\mathrm{TiO}_{2}$ : 1.1-fold, $\mathrm{P}=0.037$ ) following $0.1 \mathrm{mg} / \mathrm{ml}$ particle treatment. Furthermore, significant differences between the levels induced by different doses of PMMA and cpTi particles were observed ( $\mathrm{P}=0.05$; Fig. $6 \mathrm{~B})$.

MCP1 protein synthesis was downregulated in human osteoblasts, whereas upregulation was visible in human macrophages. For all particle types, dose-dependent differences were observed in osteoblastic cells, with significant differences 

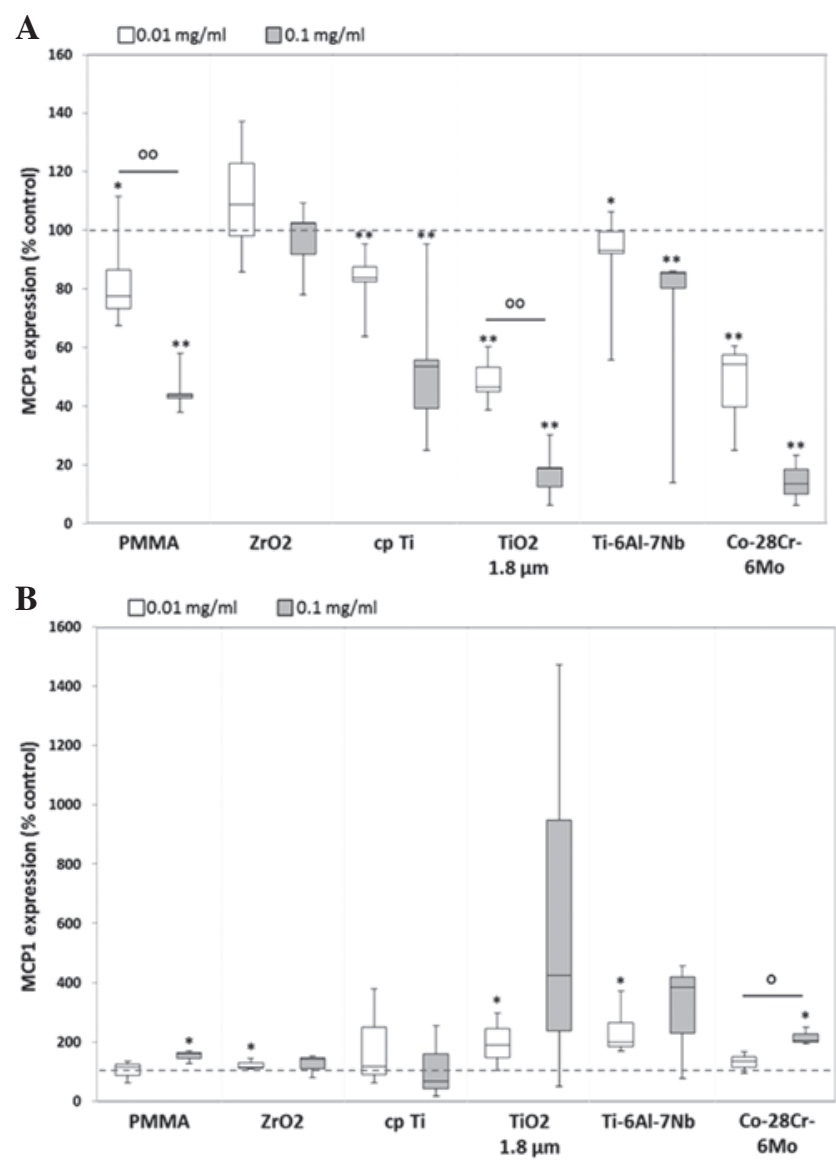

Figure 7. Release of MCP1 by human (A) osteoblasts and (B) macrophages. Cells were cultivated under standard culture conditions and later treated with the respective particles for $48 \mathrm{~h}$. Subsequently, cell culture supernatants were collected and analyzed using multiplex enzyme-linked immunosorbent assays (osteoblasts, $\mathrm{n} \geq 3$; macrophages, $\mathrm{n}=3$ ). MCP1 contents are displayed relative to the untreated control. ${ }^{*} \mathrm{P} \leq 0.05$ and ${ }^{* *} \mathrm{P}<0.01$ vs. particle exposure. ${ }^{\circ} \mathrm{P} \leq 0.05$ and ${ }^{\circ} \mathrm{P}<0.01$ vs. $0.01 \mathrm{mg} / \mathrm{ml}$ (Mann-Whitney $\mathrm{U}$ test). MCP1, monocyte chemoattractant protein-1; PMMA, polymethylmethacrylate; $\mathrm{ZrO}_{2}$, zirconiumoxide; $\mathrm{TiO}_{2}$, titanium dioxide.

between the doses of PMMA [0.8-fold decrease $(0.01 \mathrm{mg} / \mathrm{ml})$ vs. 0.4 -fold decrease $(0.1 \mathrm{mg} / \mathrm{ml}), \mathrm{P}=0.002]$ and $\mathrm{TiO}_{2}[0.5$-fold decrease $(0.01 \mathrm{mg} / \mathrm{ml})$ vs. 0.2 -fold decrease $(0.1 \mathrm{mg} / \mathrm{ml})$, $\mathrm{P}=0.002]$ (Fig. 7A). Notably, treatment with the higher particle concentration resulted in markedly lower protein contents after $48 \mathrm{~h}$. This was in contrast to that in human macrophages, wherein exposure to $0.1 \mathrm{mg} / \mathrm{ml}$ particle suspension generally led to a higher induction of MCP1 protein (with the exception of cpTi) (Fig. 7B).

Apart from its function in the developmental regulation of blood vessels, VEGF is also involved in the migration of monocytes and macrophages (4). In human osteoblasts, VEGF expression levels were mainly increased following exposure to lower particle concentration. However, the higher particle dose led to a downregulation of VEGF, with the exception of PMMA and Ti-6Al-7Nb. Significant differences between the protein levels induced by the two concentrations were only shown for Co-28Cr-6Mo, whereby the lower particle dose induced greater expression of VEGF protein [1.3-fold $(0.01 \mathrm{mg} / \mathrm{ml})$ vs. 0.8 -fold $(0.1 \mathrm{mg} / \mathrm{ml}), \mathrm{P}=0.05]$ (Fig. 8A). In human macrophages, marked differences between the doses were observed for each particle, however, these were not identified to be statistically significant.
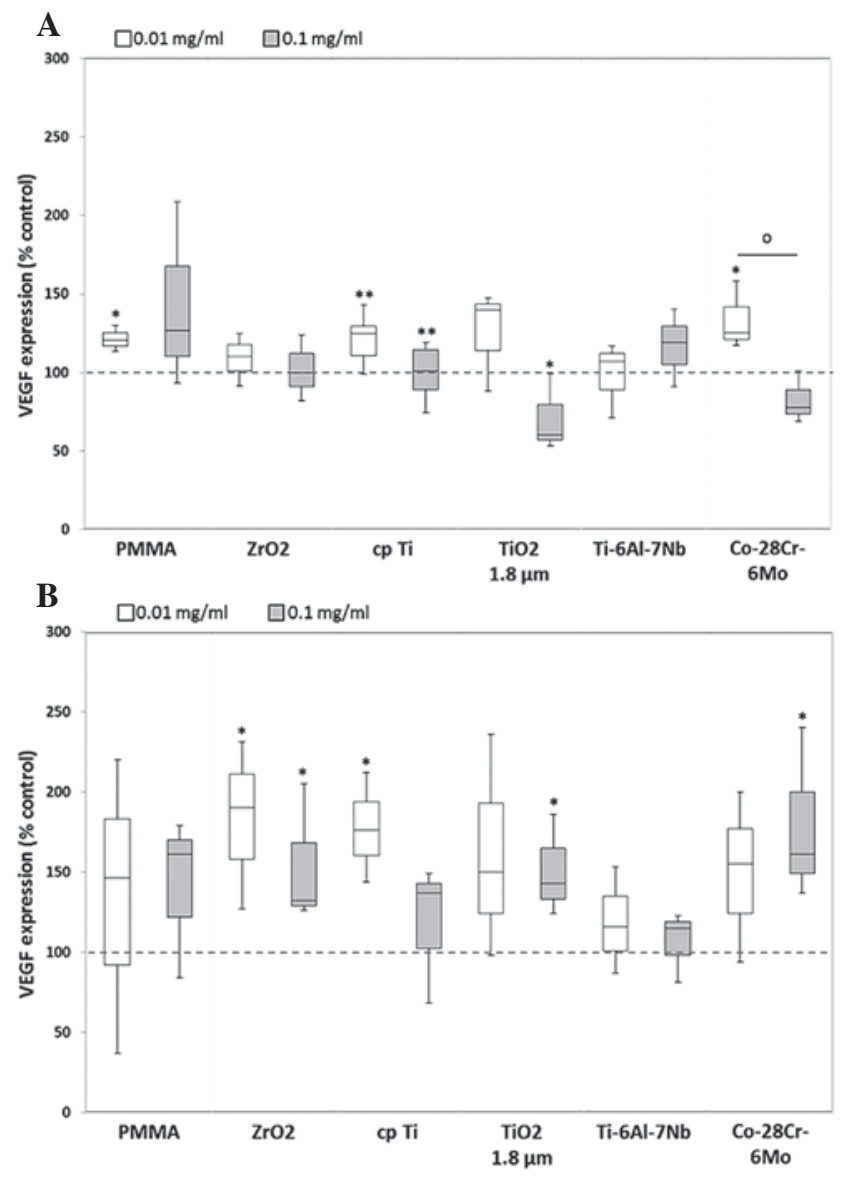

Figure 8. Release of VEGF by human (A) osteoblasts and (B) macrophages. Cells were cultivated under standard culture conditions and later treated with the respective particles for $48 \mathrm{~h}$. Subsequently, cell culture supernatants were collected and analyzed using multiplex enzyme-linked immunosorbent assays (osteoblasts, $n \geq 3$; macrophages, $n=3$ ). VEGF contents are displayed relative to the untreated control. ${ }^{*} \mathrm{P} \leq 0.05$ and ${ }^{* *} \mathrm{P}<0.01 \mathrm{vs}$. particle exposure. ${ }^{\circ} \mathrm{P} \leq 0.05$ vs. $0.01 \mathrm{mg} / \mathrm{ml}$ (Mann-Whitney U test). VEGF, vascular endothelial growth factor; PMMA, polymethylmethacrylate; $\mathrm{ZrO}_{2}$, zirconiumoxide; $\mathrm{TiO}_{2}$, titanium dioxide.

Furthermore, compared with the unstimulated cells, VEGF release was more strongly induced following exposure to the lower particle concentration of the references $\mathrm{ZrO}_{2}$ (1.9-fold, $\mathrm{P}=0.037)$, cpTi (1.8-fold, $\mathrm{P}=0.037$ ) and $\mathrm{TiO}_{2}(1.5$-fold).

\section{Discussion}

In recent decades, the development of modern endoprosthetic implants and novel bearing surfaces has been promoted in orthopedic surgery $(24,25)$. Nevertheless, the generation of prosthetic wear particles resulting in osteolytic processes has not yet been overcome. The specific biological reactions are dependent on particle type, shape, size and quantity, as well as the patient's individual genetic variations $(17,24)$. Aside from the monocyte/macrophage cell lineage, a number of other cell types, such as fibroblasts, lymphocytes, osteoprogenitor cells, and osteoblasts, have been found in the periprosthetic tissue of patients, constituting a chronic inflammatory signal (25).

The aim of the present study was to identify the initial effects within the first $48 \mathrm{~h}$ of particle exposure on cytokine release and matrix degradation by human osteoblasts and 
macrophages. Therefore, cells were exposed to cemented hip stem-derived particles of Co-28Cr-6Mo and Ti-6Al-7Nb, which were generated in a special wear simulator by micromotions between hip stem and cement mantle (1). Furthermore, reference particles of cpTi, $\mathrm{TiO}_{2}, \mathrm{PMMA}$ containing $\mathrm{ZrO}_{2}$, and $\mathrm{ZrO}_{2}$ alone were used. Comparability of all particles was achieved due to their similar mean size range of $1.75 \mu \mathrm{m}$ $\left(\mathrm{ZrO}_{2}\right)$ to $4.4 \mu \mathrm{m}$ (Ti-6Al-7Nb). Additionally, the generated test particle conglomerates contained similar contents of metallic and bone cement particles (20).

In contrast to our previous studies that investigated the particle effects on osteoblastic matrix production and cytokine release $(4,17)$, in the current study, it was determined which cell type (osteoblasts and macrophages) contributes the most to matrix degradation and inflammation following exposure to wear particles.

As mentioned above, the effect of different types of metallic and bone cement particles have previously been determined on collagen type 1 production in human osteoblasts $(4,17)$. In these instances, exposure to wear particles resulted in decreased collagen type 1 synthesis and increased MMP1 production. Additionally, cell viability was clearly restricted and apoptosis induced compared with the unstimulated osteoblasts $(4,17)$. These results indicated that bony cells are already involved in matrix degradation, resulting in limited implant integration into the bone stock. Thus, the present study examined the release of different MMPs by osteoblasts and macrophages, in order to determine their contribution to matrix degradation. In addition, the expression of TIMPs was also analyzed. The four TIMPs have been identified to bind in a 1:1 stoichiometry to all MMPs to inhibit their action. The balance between activated MMPs and free TIMPs defines overall MMP activity (5). It was previously shown that specific MMPs and TIMPs were upregulated in the periprosthetic tissue participating in bone resorption and therefore implant failure (5). In accordance with our previous studies $(4,17)$, high levels of MMP1 were detected to be released by human osteoblasts following exposure to Ti-6Al-7Nb hip stem particles. Additionally, in the present study, MMP1 expression was also induced in human macrophages following treatment with Ti-6Al-7Nb particles as well as cpTi and $\mathrm{TiO}_{2}$. Furthermore, particles from Ti-6Al-7Nb and cpTi induced the highest MMP8 expression levels in the two cell types. MMP1 and MMP8 are collagenases that are known to exhibit a direct effect on collagen type 1 disruption (5). Additionally, in macrophages, high MMP3 and MMP10 expression rates were determined following exposure to hip stem-derived particles and cpTi. These matrix degrading stromelysins are known to bind glycoproteins (e.g. proteoglycans, fibronectin and elastin) of the extracellular matrix (5). Both lysosomal enzymes (collagenases and stromelysins) were identified as bone resorbing mediators by their involvement in bone catabolism and reorganization of the organic extracellular matrix $(2,24)$. The results of the present study indicate that matrix degradation could be promoted by the two cell types; however the effect of the released MMPs was not verified. Using multiplex technology for the detection of several MMPs, differences between zymogens and active forms of MMPs were not detected. Therefore, cleavage experiments are required to confirm the degradation effects of the MMPs on the ECM. Nevertheless, activated forms of MMP1 and MMP13 have previously been identified in the periprosthetic tissue (5) suggesting a direct effect of MMP1 released by osteoblastic cells on collagen type 1 disruption, wherein particles from titanium materials have the strongest effects on degradation processes, which is consistent with results from other studies $(15,26)$. Sasaki et al (27). determined a significant upregulation of TIMP1, 2 and 3 mRNA, and decreased TIMP4 mRNA in the periprosthetic tissue. In the present study, decreased levels of TIMP1 and 2 were verified in human osteoblasts and macrophages following particle exposure. Notably, in human osteoblasts, the two TIMPs were significantly downregulated after treatment with all hip stem-derived particles as well as cpTi particles whereas in macrophages, only a significant decreased TIMP2 expression rate was determined as a response of metallic particle exposure. Furthermore, no TIMP3 or TIMP4 protein could be detected in particle-treated and control cell cultures (osteoblasts and macrophages). These results indicate that the activity of MMPs is not inhibited by TIMPs, thus resulting in unrestricted matrix degradation.

Particle-induced communication between macrophages, osteoblasts, fibroblasts and other cells is mediated by the release of several inflammatory mediators including IL-6, IL-8 and MCP1 $(24,25)$. When using self-generated particles there is nevertheless the possibility of a contamination with lipopolysaccharides (LPS) ensuring an undefined differentiation process in macrophages. As a result, LPS-mediated cytokine release by macrophages may overlap with the effects of particle exposure. Avoiding a contamination with LPS was thus important in the present study. Therefore, sterile commercially available hip stems as well as bone cement that had not been in contact with human tissue were used in order to minimize the possibility of contamination with LPS. Additionally, sterilization of particles with gamma radiation should subsequently ensure less toxicity (28).

Of the cytokines that have a chemotactic effect on peripheral monocytes and macrophages, MCP1 is one of the most important (24). Additionally, the release of VEGF by cells into the periprosthetic tissue can activate the monocyte migration and fibroblast proliferation (29). In a previous study, high VEGF levels were determined following particle exposure in osteoblastic cells, but only a weak expression rate of MCP1 (4). In the current study, the increase in VEGF levels were confirmed; however a difference in MCP1 levels was identified with MCP1 upregulation as it was determined in human macrophages. As a result, the release of the proinflammatory cytokines may be upregulated exponentially by high levels of MCP1 (30). These results indicate that macrophages contribute principally to monocyte/macrophage recruitment whereas osteoblasts may contribute indirectly by the release of VEGF.

The two cells types demonstrated increased levels of IL-6 expression following particle exposure. As a result of high IL-6 levels, the gene expression of procollagens in osteoblasts is suppressed (30). As osteoblasts exhibited decreased procollagen type I expression following particle exposure $(4,17)$, this suggested a correlation between high IL-6 and low procollagen levels. Macrophages may therefore have an additive effect on the inhibition of procollagen production as they were also shown to upregulate the levels of IL-6 protein synthesis. Concurrent with 
the results of Fritz et al $(31,32)$, increased levels of IL-8 were identified in human osteoblasts. As a result, in the periprosthetic tissue, granulocytes may be activated, directly promoting bone degradation by the release of elastase and cathepsin G (30). Aside from the release of diverse MMPs and downregulation of TIMPs, osteoblasts and macrophages directly influence matrix degradation and therefore osteolysis by the sustained release of proinflammatory cytokines following particle exposure. Nevertheless, it was demonstrated that hip stem-derived particles of Ti-6Al-7Nb and Co-28Cr-6Mo as well as cpTi as a reference have a significant, positive regulatory effect on cytokine production. Notably, the results suggest that lower particle concentrations often have a greater effect on mediator release, indicating that cells react sensitively to the presence of low particle densities. Due to particle agglomeration at higher concentrations, cells were not able to phagocytose these particles to induce cellular inflammatory cascades. In this context, the particles should not exhibit $>10 \mu \mathrm{m}$ in size (25).

In conclusion, the results suggest that human osteoblasts are directly involved in the proinflammatory cascade of bone matrix degradation. Additionally, the simultaneous activation and recruitment of monocytes/macrophages may boost osteolytic processes in the periprosthetic tissue. By downregulation of TIMPs production and the concomitant upregulation of MMPs, bone matrix will be destroyed. Nevertheless, in future studies, it should be distinguished whether released MMPs will be already activated to function as matrix-degrading enzymes. Once they have been activated, bone formation around implants may be suppressed, resulting in implant failure.

\section{Acknowledgements}

This study was supported by the FORUN program of the University Medical Center Rostock. The authors would like to acknowledge Dr Petra Müller (Department of Cell Biology, University Medical Center Rostock) who provided technical support for the Bio-Plex assays.

\section{References}

1. Bader R, Steinhauser E, Holzwarth U, Schmitt $M$ and Mittelmeier W: A novel test method for evaluation of the abrasive wear behaviour of total hip stems at the interface between implant surface and bone cement. Proc Inst Mech Eng H 218: 223-230, 2004.

2. Jacobs JJ, Roebuck KA, Archibeck M, Hallab NJ and Glant TT: Osteolysis: Basic science. Clin Orthop Relat Res 393: 71-77, 2001.

3. Willert HG and Semlitsch M: Tissue reactions to plastic and metallic wear products of joint endoprostheses. Clin Orthop Relat Res 333: 4-14, 1996.

4. Lochner K, Fritsche A, Jonitz A, Hansmann D, Mueller P, Mueller-Hilke B and Bader R: The potential role of human osteoblasts for periprosthetic osteolysis following exposure to wear particles. Int J Mol Med 28: 1055-1063, 2011.

5. Syggelos SA, Aletras AJ, Smirlaki I and Skandalis SS: Extracellular matrix degradation and tissue remodeling in periprosthetic loosening and osteolysis: Focus on matrix metalloproteinases, their endogenous tissue inhibitors and the proteasome. Biomed Res Int 2013: 230805, 2013.

6. Tuan RS, Lee FY, T Konttinen Y, Wilkinson JM and Smith RL; Implant Wear Symposium 2007 Biologic Work Group: What are the local and systemic biologic reactions and mediators to wear debris and what host factors determine or modulate the biologic response to wear particles? J Am Acad Orthop Surg 16 (Suppl 1): 42-48, 2008.
7. Nakashima Y, Sun DH, Maloney WJ, Goodman SB, Schurman DJ and Smith RL: Induction of matrix metalloproteinase expression in human macrophages by orthopaedic particulate debris in vitro. J Bone Joint Surg Br 80: 694-700, 1998.

8. Diehl P, Hantke B, Hennig M, Tschesche H, Mittelmeier W, Schmitt M and Muehlenweg B: Protein expression of MMP-13, uPA and PAI-1 in pseudocapsular and interface tissue around implants of loose artificial hip joints and in osteoarthritis. Int J Mol Med 13: 711-715, 2004.

9. Nich C, Takakubo Y, Pajarinen J, Ainola M, Salem A, Sillat T, Rao AJ, Raska M, Tamaki Y, Takagi M, et al: Macrophages-Key cells in the response to wear debris from joint replacements. J Biomed Mater Res A 101: 3033-3045, 2013.

10. Rooprai HK, Rucklidge GJ, Panou $C$ and Pilkington GJ: The effects of exogenous growth factors on matrix metalloproteinase secretion by human brain tumour cells. Br J Cancer 82: 52-55, 2008.

11. Tasaki K, Shintani Y, Saotome T, Andoh A, Fujiyama Y, Hozawa $\mathrm{S}$ and Bamba T: Pro-inflammatory cytokine-induced matrix metalloproteinase-1 (MMP-1) secretion in human pancreatic periacinar myofibroblasts. Pancreatology 3: 414-421, 2003.

12. Andersson MK, Lundberg P, Ohlin A, Perry MJ, Lie A, Stark A and Lerner UH: Effects on osteoclast and osteoblast activities in cultured mouse calvarial bones by synovial fluids from patients with a loose joint prosthesis and from osteoarthritis patients. Arthritis Res Ther 9: R18, 2007.

13. Kular J, Tickner J, Chim SM and Xu J: An overview of the regulation of bone remodelling at the cellular level. Clin Biochem 45: 863-873, 2012.

14. Koreny T, Tunyogi-Csapó M, Gál I, Vermes C, Jacobs JJ and Glant TT: The role of fibroblasts and fibroblast-derived factors in periprosthetic osteolysis. Arthritis Rheum 54: 3221-3232, 2006.

15. Yao J, Cs-Szabó G, Jacobs JJ, Kuettner KE and Glant TT: Suppression of osteoblast function by titanium particles. J Bone Joint Surg Am 79: 107-112, 1997.

16. Goodman S, Aspenberg P, Song Y, Knoblich G, Huie P, Regula D and Lidgren L: Tissue ingrowth and differentiation in the bone-harvest chamber in the presence of cobalt-chromium-alloy and high-density-polyethylene particles. J Bone Joint Surg Am 77: 1025-1035, 1995.

17. Schulze C, Lochner K, Jonitz A, Lenz R, Duettmann O, Hansmann D and Bader R: Cell viability, collagen synthesis and cytokine expression in human osteoblasts following incubation with generated wear particles using different bone cements. Int J Mol Med 32: 227-234, 2013.

18. Trindade MC, Lind M, Sun D, Schurman DJ, Goodman SB and Smith RL: In vitro reaction to orthopaedic biomaterials by macrophages and lymphocytes isolated from patients undergoing revision surgery. Biomaterials 22: 253-259, 2001.

19. Keeney M, Waters H, Barcay K, Jiang X, Yao Z, Pajarinen J, Egashira K, Goodman SB and Yang F: Mutant MCP-1 protein delivery from layer-by-layer coatings on orthopedic implants to modulate inflammatory response. Biomaterials 34: 10287-9525, 2013.

20. Bader R, Mittelmeier W, Steinhauser E, Brehm P, Brem R, Tübel J, Choungthong P, Winklmair D, Schmitt $M$ and Holzwarth U: Abriebverhalten von zementierten Hüftendoprothesen-Stielen-Einfluss der Knochenzement-Zusammensetzung. Materialprüfung 47: 175-180, 2005 (In German).

21. Lenz R, Mittelmeier W, Hansmann D, Brem R, Diehl P, Fritsche A and Bader R: Response of human osteoblasts exposed to wear particles generated at the interface of total hip stems and bone cement. J Biomed Mater Res A 89: 370-378, 2009.

22. Park EK, Jung HS, Yang HI, Yoo MC, Kim C and Kim KS: Optimized THP-1 differentiation is required for the detection of responses to weak stimuli. Inflamm Res 56: 45-50, 2007.

23. Brew K, Dinakarpandian D and Nagase H: Tissue inhibitors of metalloproteinases: Evolution, structure and function. Biochem Biophys Acta 1477: 267-283, 2000.

24. Bitar D and Parvizi J: Biological response to prosthetic debris. World J Orthop 6: 172-189, 2015.

25. Goodman SB, Gibon E and Yao Z: The basic science of periprosthetic osteolysis. Instr Course Lect 62: 201-206, 2013.

26. Vermes C, Chandrasekaran R, Jacobs JJ, Galante JO, Roebuck KA and Glant TT: The effects of particulate wear debris, cytokines and growth factors on the functions of MG-63 osteoblasts. J Bone Joint Surg 83-A: 201-211, 2001. 
27. Sasaki K, Takagi M, Mandelin J, Takei I, Santavirta S, Ida H, Ogino T and Konttinen YT: Quantitative analysis of mRNA expression of TIMPs in the periprosthetic interface tissue of loose hips by real-time PCR system. J Biomed Mater Res 58: 605-612, 2001.

28. Naidu MD, Chander R and Nair PM: Effect of gamma irradiation on chemical and biological properties of lipopolysaccharides from Salmonella typhimurium. Indian J Exp Biol 36: 588-92, 1998.

29. Zittermann SI and Issekutz AC: Endothelial growth factor VEGF and bFGF differentially enhance monocyte and neutrophil recruitment to inflammation. J Leukoc Biol 80: 247-257, 2006.
30. Otto M, Kriegsmann J, Gehrke T and Bertz S: Wear particles: Key to aseptic prosthetic loosening? Pathologe 27: 447-460, 2006 (In German).

31. Fritz EA, Glant TT, Vermes C, Jacobs JJ and Roebuck KA: Titanium particles induce the immediate early stress responsive chemokines IL-8 and MCP-1 in osteoblasts. J Orthop Res 20: 490-498, 2002.

32. Fritz EA, Jacobs JJ, Glant TT and Roebuck KA: Chemokine IL-8 induction by particulate wear debris in osteoblasts is mediated by NF-kappaB. J Orthop Res 23: 1249-1257, 2005. 